\title{
Metacommunity research can benefit from including context-dependency
}

\author{
Jurek Kolasa, Matthew P. Hammond, and Joyce Yan \\ Department of Biology, McMaster University, Hamilton, Ontario, Canada
}

Emails: kolasa@mcmaster.ca; $\underline{\text { mhammond@gmx.com; yanj62@mcmaster.ca }}$

Keywords: context-dependency, metacommunity, habitat heterogeneity, specialization, biodiversity, community, dispersal, species interactions, meta-habitat, testability

Correspondence: Department of Biology, McMaster University, Hamilton, ON, L8S 4K1, Canada, email: kolasa@mcmaster.ca, tel: +1 289-237-8622

Contributions: JK conceived and wrote the first draft of the paper, JK and $\mathrm{MH}$ wrote the paper, JY and JK developed MC simulation model and JK analyzed the output. JK and MH contributed substantially to the revisions. 


\begin{abstract}
:
Context-dependency, C-D, of outcomes occurs when several factors affect a focal metric. Remedies for treating milder cases of C-D are readily available but severe cases, where some contributory factors cause non-linear changes in others, escaped routine scrutiny. This poses a universal challenge to standard research strategies. We suggest that metacommunity framework may be particularly vulnerable because its core notions (habitat structure, dispersal, and species interactions) are functionally entangled. When these notions are generalized to include many species and situations, they become interdependent. To illustrate the significance of such interdependence, we test two hypotheses. One that holding combination of parameters constant in all but one dimension, can alter inference of a study and the second that the severity of context-dependency increases when core metacommunity dimensions interact and transform one another through a variety of mechanisms. The results support these ideas and imply that CD predicts a dauntingly vast space of possible empirical outcomes and interpretations, most of which can arise from reciprocal interactions among metacommunity core dimensions. We proffer that an adaptable and structured use of macro-variables is a place to start investigating metacommunity mechanisms more efficiently.
\end{abstract}




\section{Context-dependency in metacommunities}

The metacommunity perspective (MC) grows fast as a general framework for linking a range of ecological processes in landscapes. As an incipient theory, MC has built on several elementary processes to predict responses in variables of a higher-level system - an aggregate of communities/ecosystems - such as biodiversity, ecosystem functioning or stability. Its foundations arose from competition tradeoffs models, but the further growth helped identify aspects in need of expansion (Brown et al. 2017), refinement, rethinking. For example, heterogeneity has an integral role in the framework and should be included to make tests of MC robust (Grainger \& Gilbert 2016). Further, new axes for a better treatment of trophic relationship in space were proposed (Guzman et al. 2019). They looked at ways by which environmental heterogeneity imposes constraints on trophic interactions through movement and local success of species. Together, heterogeneity represents a complex dimension of physical and biological phase space that shapes the distributions of species. No doubt, other dimensions (e.g., types of species interactions from negative to positive, or extent of habitat modification arising from metacommunity dynamics) may be required before we have a more complete framework.

The many drivers of metacommunity dynamics cannot avoid conceptual and practical challenges posed by multidimensionality. Multidimensionality occurs when several variables may jointly determine an ecological outcome or dynamic. It is pervasive in ecology under various guises (e.g., contingency; Lawton 1999) and has been recognized as severely challenging our ability to predict future states of communities and their ecosystem consequences (e.g., Arnoldi et al. 2019, Marleau \& Guichard 2019). The core problem is that where multiple variables jointly determine an outcome, a single ecological process (e.g., dispersal) can lead to clear differences in slightly 
different contexts. For instance, fig trees introduced outside native range change from having negligible ecosystem effects to being invasive depending on whether their pollinating wasps are present. Further, whether or not wasps colonize depends on scale-dependent interactions involving competing pollinators and natural enemies (Wang et al. 2015). Fig tree effects thus depend on the unique confluence of dispersal patterns and species interactions.

An important consequence of C-D is that inferences drawn in one setting do not apply in another and require multifaceted considerations of complexity (Fulton et al. 2019). Furthermore, predicting system-level properties of high-dimensional systems is further complicated by geometric effects (Orr et al. 2020) because in high dimensions there are more ways for two outcomes to be more different, than ways to be more similar. But despite the likelihood of considerable $\mathrm{C}-\mathrm{D}$ in metacommunities, theoretical treatments of $\mathrm{C}-\mathrm{D}$ are few and limited to single communities (e.g., Song et al. 2020). As a result, if it is also common in metacommunities, CD may impose quite severe limits on predicting biological outcomes of their different processes.

Here we focus on the idea that in complex and interactive systems such as MCs, the multidimensionality makes the context-dependency of findings more likely. If correct, this may limit MC advances unless C-D implications are grasped more fully (Figure 1). We illustrate the problem of C-D using a new model of foundational metacommunity dimensions, highlighting:

(1) two general forms of context-dependency - directional and reciprocal - that vary in severity of producing outcomes that vary significantly with ecological context.

(2) two applied problems arising from these forms that may complicate the prediction and understanding of metacommunities, and 
(3) research directions and strategies for coping with context-dependency and for using it to advance ecological understanding.

\section{Context-dependency in a model}

We developed the Unified Metacommunity Model (UMM) to expose how some fundamental dimensions of metacommunities might interact to produce context-dependency (Fig. 1).

The model's dimensions - described below - enable the testing of general postulates. But as these dimensions are macrovariables, they also allow expansion to include subdimensions such as demographics, dispersal strategies, behavioral response, or configuration of patches. The approach is therefore expected to encompass the range of reported mechanisms and dynamics (see Supplementary Materials for details and Box 1 for short definitions of common terms).

\section{Box 1. Terms}

Patch - an area in a landscape that is recognizable by some species as different from other areas and that allows a local population of a least some species to have their own unique dynamics distinguishable from other areas.

Dimension - an abstract macro-variable that is a composite of any number of converging processes or features jointly describing its role in shaping, for example, population size, stability, biodiversity, or ecosystem productivity.

Context-dependency (short) - when the outcome of a process (e.g., dispersal) changes (in sign or strength) in response to multiway interactions with other system dimensions (Fig. 1d). We distiguish: static and dynamic C-D. 
These four dimensions organize processes of interest in ways not unlike those established in metacommunity research since its inception. They recognize that movement of organisms in space, features of the space, traits of the organisms, and their interactions with space and each other are major determinants of various aspects of local and regional biodiversity. Yet, as macrovariables, they allow moving between general and specific questions and tests, without missing the broader picture by either advancing general postulates or by exploring specific aspects of a macro-variable.

\section{Inter-habitat differences (heterogeneity)}

We define inter-habitat differences, IH $\Delta$, as a function of species perceptions - a habitat is heterogeneous only to the extent to which differences among patches interfere with species growth rate, $r$. This dimension assumes continuous values on arbitrary scale from 0 to 1 , where 0 signifies a homogeneous matrix and 1 signifies patch differences high enough to prevent species occupies a single patch from occupying any other patch - a two bookend-like case of counterfactual that defines the state space (Deutsch 2013). In principle, IH $\Delta$ is based on the totality of conditions a patch presents to species of the regional pool and on barriers separating them, including distance. This definition of IH $\Delta$ implies that each species should experience landscape structure as different and that its experience changes with change in patch characteristics, including its complement of other species and available resources. Species distributions in Gorongosa National Park (Box 2), for instance, relate to organism perceptions of how dangerous diverse habitat types are. Removal of predators reduced heterogeneity in those perceptions as predators make some areas more dangerous than others. This led to prey species 
operating in more homogeneous landscape (Atkins et al. 2019; Pansu et al. 2019). Importantly, this change occurs even if heterogeneity perceived by an outsider has not changed.

\section{Box 2. Gorongosa example.}

After several top predator species disappeared from Gorongosa National Park,

Mozambique, several major changes in the ungulate community its habitat use have occurred.

- Trophic niche differences decreased as indexed by diet composition (in contrast with the near-complete niche separation in a reference community in Kenya; (Pansu et al. 2019));

- Distribution across habitats expanded to include a larger mosaic of habitats that species used before the loss of predators (Atkins et al. 2019);

- Populations of some species gained resources of high quality and increased numbers and body condition (bushbuck);

- An overlap in spatial and dietary habitat uses increased;

- Predation by a reduced number of lions failed to control abundance and distribution of ungulates.

The ensuing C-D primary effects involved:

- niches - a key concept in MC theory (e.g., Leibold et al. 2020; Thompson et al.

2020; Guzman et al. 2019) - drastically changed; this led to

- a reduction of effective habitat heterogeneity as perceived by species, which resulted in

- easier dispersal across habitats and, subsequently: 
- an emergence of potential competitive links among species not competing prior to the loss of predators - a sign change in interspecific interactions from " 0 ” to "_،.

- Together, this led to major differential shifts in access to quantity and quality of resources.

Although these changes may be explainable, the literal lessons are not transferrable to other systems as different vegetation patterns or different predator assemblage might produce different outcomes.

\section{Dispersal}

We base effective dispersal rate, or just dispersal rate (Leibold et al. 2004; Guichard et al. 2019) on the probability of colonizing rather than general mobility - the number of individuals leaving a source patch individuals dispersing or moving (sensu Guzman et al. 2019). We chose this metric because it directly focuses on individuals added to and participating in a local network of community processes. Mobility indeed matters but may depend on short-term patch conditions (positive and negative interactions, resources, abiotic quality). As these conditions are being modified by species activities, using mobility may introduce greater uncertainty of predictions. The interpretation of spatial transfer of individuals we adopt here ties the effective dispersal to $\mathrm{IH} \Delta$ above and, indirectly, to species composition in patches that species use as steppingstones to the final receiving patch. This view opens a new avenue for questions and hypotheses. For example, if a patch is dominated by positive interactions, and the mean specialization of community members is high, effective dispersal into that patch will increase $\mathrm{S}$ until communal carrying capacity is reached.

\section{Specialization}


We treat specialization as a breadth of species response to collection of diverse habitats. This view captures combined effect of habitat properties, species traits, presence of predators, competitors, mutualists, and other factors. Specialization can be evaluated through distribution on a gradient of inter-habitat differences, weighted by population density on that gradient. Because species response is context-dependent and often non-linear (Newman et al. 2019), we propose a modified approach to account for the role of traits in MC dynamics. This new view partially overlaps with the popular version of the realized niche concept, including the nichehabitat relationship developed by (Chase \& Leibold 2003). Specialization we propose differs from the niche applications by its inherent adjustability, by reflecting history, priority effects, and by combining the effects of abiotic (including space) and biotic interactions, including indirect ones (cf. Thompson et al. 2020). Combining the abiotic and biotic effects is convenient as: a) we need a concise list of general dimensions that can still include more specific factors and b) blending the distinction between biotic density-dependence and responses to abiotic factors, which is not as obvious as common references might suggest. They are often used jointly anyway when these two categories of factors interact (MacDougall et al. 2018).

\section{Species Interactions}

A general approach to MC structure and dynamics requires that it accommodates its most recognized feature - competition cf. (Leibold et al. 2004; Logue et al. 2011; Thompson et al. 2020), other direct interactions such as predation (Abrams 2007; Jabot \& Bascompte 2012; Ryberg et al. 2012; Vanschoenwinkel et al. 2013; Haegeman \& Loreau 2014; Liao et al. 2020), mutualism (Yu et al. 2004), parasitism, commensalism as well as a high number of possible indirect interactions (e.g., Miller \& Kneitel 2005; Gravel et al. 2010; Miller \& terHorst 2012). Although most work focused on a single or few interaction types, an interaction network active 
in natural MC is likely to involve many. Extending MC approach to ecosystem properties makes this network even more complex (e.g., Massol et al. 2011), and produces correspondingly revealing and unexpected outcomes such as emergent patterns of interactions, non-linearities, and spontaneous self-organization (Filotas et al. 2010; Gonzalez et al. 2020), along with habitat modifications.

To accommodate a wide range of ecological interactions, we define interactions as a generalized impact of one species on another. This impact is scaled from -1 to 1 , with values around 0 corresponding to no interaction. The mode of interaction may involve commonly discussed types (competition, predation, mutualism, parasitism) and indirect interactions, including those mediated by the environment (e.g., creosote bush that facilitates growth of saguaro cactus via microclimate amelioration).

The UMM model in its design allows interactions among the four core metacommunity dimensions, represented by the arrows in Figure 1. These links reveal some already recognized forms of C-D. Possibly the earliest recognized of these is dispersal-induced interactions where the sign or magnitude of species interactions depends on dispersal, such as in prey escaping predation.

Another well-known form of C-D is what we call filtered interactions, where the local environment filters the community to a subset of species and modulates their interactions (Cadotte \& Tucker 2017; Boulangeat et al. 2012). Other forms are less recognized. Conditiondependent dispersal is where dispersal itself changes in rate depending on species interactions such as strong local competition (Fronhofer et al. 2015). The contingencies possible in MCs continue with pairwise interactions and beyond and extend to interactions involving three or four 
dimensions (Table 1). Indeed, a proposition for future research is that all such interactions among key dimensions may have the power to diversify MC outcomes.

\section{Directional and reciprocal C-D}

We used the UMM (see Box 3; Appendix 1 for details) to evaluate the proposition that, in high dimensional systems, slight changes in one or more dimensions can profoundly change outcomes and interpretation of metacommunity phenomena. We focused on the effect of species interactions on metacommunity states because this factor is understudied compared to other factors. We further posited that interacting metacommunity dimensions could result in two basic types of C-D arising from the ways in which underlying system dimensions or factors can interact (Fig. 2). We illustrate these forms of C-D below with simulation results, literature examples and the interpretational challenges they pose for metacommunity research.

\section{Box 3. Model implementation}

We ran the UMM in a NetLogo package parameterized with the following general features (details in Appendix 1):

Habitat was represented as a mosaic of square patches in a regional meta-habitat with diverse suitability and resource (energy). Patch suitability values (fixed range of conditions that species must be able to use) and resource quantities were randomly assigned at the beginning of a simulation. Resources were regenerated at a random rate. 
Species were represented by individuals (agents) that reproduce or move depending on the quality of the patch (suitability and state of resources) they reached in the previous step. Community population growth was limited by a global carrying capacity. Reproduction and dispersal rates were random but could be modified by additional variables (e.g., proximity of suitable patches).

Dispersal occurred when an individual obtained enough energy. Dispersal direction was random as was a decision whether to disperse or reproduce. Individuals reaching a patch with an adequate supply of energy, gained energy. Surviving and moving cost energy. Energetic cost of moving differed among species and species categories (e.g., specialists gain more from finding a suitable patch than generalists).

Species interactions could be positive (mutualism, facilitation), negative (competition, predation, inhibition), or neutral (no impact or cancelling indirect impacts). Interactions occurred when an agent meets other agents (conspecific or other species) on a patch. Interaction strength and sign were set to give specialists some advantages when they meet generalists.

What we term directional C-D is a situation familiar to many ecologists. Here, the effect or outcome of one driver is directly modified by one or more other variables (Fig. 2a,c). An example of directional C-D, increasingly recognized at the local scale, is that an interspecific interaction can change in sign and magnitude depending on its biotic or abiotic context 
(Chamberlain et al. 2014; Song et al. 2020). Here, the effect of one species on another is mediated by other environmental or biotic factors.

\section{Type 1. Directional context-dependency}

A general test for the existence of directional context-dependency is that holding combination of parameters in three dimensions constant while changing values along one dimension will alter inference of a study (Hypothesis 1). Specifically, we propose that for any class of inter-habitat differences (small differences in poor quality habitat, small differences in high quality habitat), the remaining dimensions - species interactions, specialization, and levels of dispersal - may have a major impact on species richness by changing the processes regulating local extinction and recolonization. Simulations using the UMM confirmed that habitat differences were important in determining richness but that with a significant context-dependency: The richnessinflating effects of habitat hinged on positive interactions among specialists (Fig. 3).

The richness-inflating mechanism we detected may be similar to those described for facilitating species or ecological engineering (Zélé et al. 2018). Positive interactions have been suggested to improve environments for many species (Stachowicz 2001) or lead to alternative community states (Grilli et al. 2016). Yet our simulations single out the strong role of positive interactions involving specialists for boosting regional diversity. Specialists are typically rare and sensitive (e.g., Williams 2005) but also contribute the most to species richness in the typical local community (Kolasa \& Li 2003). These findings converge with (Yeakel et al. 2020) who focused on positive interactions that ecological engineers exhibit in a model community. They also found that species richness and stability increased with number of emerging interaction modules. In sum, habitat effects on species richness can arise from positive interactions among specialists, a process which itself is variable. In our simulations, a higher variability in richness for positive 
over negative interactions (Figure 2e), further suggests that while mutualisms boost metacommunity richness, they may do so unpredictably. Taken together, findings show that the effect of environment is knowable, but it changes with even a minor switch in context, from a specialist to generalist community and on a gradient from predatory/competitive to mutualistic interactions.

Further, five significant interactions among dimensions underscored that richness responses to one dimension were frequently modified by another (Appendix 2, for richness, S, Table 2.1 and for abundance $\mathrm{N}_{\text {all }}$, Table 2.2), consistent with a multivariate $\mathrm{C}$-D model in which multiple factors modify an ecological process (Fig 1c, d). These interdependences imply that predictions based on one or few metacommunity dimensions, such as environmental gradients alone, will necessarily fall short of the mark. This introduces an extrapolation problem for the applied science of metacommunities, where conclusions from one context do not hold in another. This problem may be acute when an influential process (e.g., specialized use of habitat) is assumed to have the same effect in another location or time, but does not because of high contextdependency (cf., Kimbro et al. 2014). In the example of Gorongosa herbivores (Box 2), the transition of bushbuck antelope from bush specialist to multi-habitat generalist hinged on cascade of factors that followed disappearance of predators. Thus, predictions based on the simple observation that bushbuck is restricted to specific landscape features would likely not apply to landscapes without the same confluence of predation, competition, and vegetation dynamics.

\section{Type 2. Reciprocal context-dependency}

A less common view of C-D is that it emerges from interdependent dimensions (e.g., Arnoldi et al. 2019). When system dimensions interact, there is potential for what we term reciprocal 
context-dependency - when two or more factors affect each other in a non-additive fashion to then determine an outcome (Fig. 3b, d). Here, non-linear relationships and feedbacks among state variables may lead to an even richer network of interdependencies. Non-linearities may indeed be common in metacommunities. Mixing distinct kinds of interspecific interactions, for instance, can dramatically alter community dynamics and community structure (e.g., Mougi \& Kondoh 2012). In such systems, predictions of dynamics, richness and community composition will be sensitive to slight changes in state variables or non-linearity in their relationships. Extreme sensitivity has been demonstrated in simulated communities where loss of (patches needed for movement) led to a cascade of diverse, including unsuspected, consequences mediated by reduction in available habitat, connectivity, dispersal limitation and other factors (Thompson et al. 2017).

To explain sensitivity of metacommunity to small parameter changes, we propose that: Severity

\section{of context-dependency increases when fundamental dimensions of metacommunities can}

interact and influence one another through various mechanisms (Hypothesis 2). A test for this

hypothesis and the existence of reciprocal C-D is whether the effects of key variables are nonadditive, such that interacting factors lead to unexpected outcomes. We predicted that, in the UMM, a confluence of factors including antagonistic interactions, specialization, inter-habitat differences, and variability of specialist species, would have a greater-than-expected negative impact on regional species diversity due to non-linear interactions among dimensions.

Species richness of generalists and specialists responded differently to available resources, with resources remaining higher when specialist diversity declines (Fig. 4A). We also found that the richness of generalists and specialists responded differently to habitat suitability, with the latter having a hump-shaped response (Fig. 4B). 
Indeed, neither food 'causes' declines in richness nor richness 'causes' declines in food. These two variables may correlate or not due to other processes. In the model, the entire food supply is available and consumed by all individuals present on a patch irrespective of their identity. Thus, a high population combined over all species on a patch, i.e., patch share of $\mathrm{N}_{\text {all }}$, inevitably depresses resources compared to patches with fewer individuals. Although patch energy regenerates, a patch does not compensate here for energy consumption through recycling, for example, as considered by others (e.g., Marleau \& Guichard 2019). Richness however may have a more complex relationship with such density or biomass gradients (Duffy 2002).

To illustrate C-D effects arising from interplay between species interactions, species specialization, and habitat properties (inter-habitat differences), we chose treatment settings that yielded middle of the range behavior of the model (similar to those in Fig 3C), with:

- High Specialization,

- Species Interactions where Specialists benefitted from meeting other specialists and generalists while generalists suffered losses, and with

- $\quad$ habitat of poor quality and Inter-Habitat differences low.

We then tested whether abundance of all species combined, $\mathrm{N}_{\text {all }}$, is a plausible explanation for the observed food decline. We found a strong relationship between habitat suitability and mean food amount per suitability class (Fig. 5A). This regularity was a mirror reflection of $\mathrm{N}_{\text {all }}$ (Fig. 5B). Relevant here is that the aggregated density of all species, $\mathrm{N}_{\mathrm{all}}$, is negatively and linearly correlated with amount of food on a patch $\left(r^{2}=0.917\right)$, which means that species dispersal, successful recruitment and habitat attributes changed directly or indirectly in response to each 
other. While revealing mechanisms contributing to this picture lies outside the scope of the paper, we note that species interactions appear to drive some of it. Specifically, we found that combined population of specialists, $\mathrm{N}_{\text {spe, }}$ initially increases, then decreases with $\mathrm{N}$ generalists, $\mathrm{N}_{\text {gen }}$ (Polynomial, quadratic regression: $\mathrm{N}_{\text {spe }}=-0.1877 \mathrm{~N}_{\text {gen }}{ }^{2}+86.124 \mathrm{~N}_{\text {gen }}-9519.5 ; \mathrm{R}^{2}=$ 0.6154, $\mathrm{n}=40, \mathrm{p}<0.00001)$. Thus, initial gains from the presence of generalists help boost specialists unless generalists increase in numbers and deplete resources - a pattern correlated with $\mathrm{S}_{\text {spe. }}$

Our findings support the idea that reciprocal influences can affect other dimensions in the $4 D$ framework and the metacommunity outcomes. In our model exercise, it appears that a species success in reaching a patch, surviving, reproducing on, and dispersing from it depends on two CD elements. One is compatibility with the non-interactive environment of the patch (abiotic and some biotic, e.g., trees and ground cover for ground rodents in a forest). Another is resources (represented as energy or 'food' in the model). As some aspects of heterogeneity can filter species distribution and local success, they will also affect food consumption differentially on patches of diverse suitability and accessibility - the result may be either dampening or amplifying inter-habitat suitability differences - a modification of the anticipated outcome (e.g., with respect to distribution, local and regional richness, variation of population and others) will ensue. The classical study of intertidal invertebrates (Paine 1984) highlights a similar observation that environmental factors, species specialization and interactions combine to produce spatial patterns that would not be predicted from individual factors alone.

The practical result of reciprocal C-D in metacommunities is that, even when accounting for important dimensions, interdependencies, and reciprocities, feedbacks among them may lead to unexpected and emergent effects. Findings therefore challenge the tacit assumption that 
metacommunities are predictable from analysis of a few key dimensions. Because the net effects of interacting variables will be hard to predict at larger metacommunity or ecosystem scales, the existence of this type of C-D is expected to lead to the predictability problem. Even with knowledge of the system states in four dimensions, their interaction over time can give rise to ecological surprises.

The reasoning above may be familiar to succession or ecosystem researchers, but it is yet not an integral part of the metacommunity theory. To be complete, MC research needs to espouse the view that in high-dimensional metacommunities the 4D dynamically adjust and re-adjust in response to each other in time and space. This represents the most severe case of C-D. It is possible that in cases where individual dimensions form a dynamic network of interdependent processes, separating their individual contributions may be difficult to achieve in a single testing step, especially with incomplete data sets. Further, we discuss ways in which ecologists might recognize, mitigate, or even benefit from the context-dependency of constituent dimensions of MC framework.

\section{$4 \mathrm{C}$-D in future metacommunity research}

\section{Implications}

The example of MC dynamics examined along one dimension revealed substantial shift among patterns (Fig. 3). These patterns may be sensitive to small changes along other dimensions that are not included in analyses, especially where species manage to modify habitat quality (Fig. 4). While researchers understand the challenge of predicting outcomes in species-rich landscapes, C$\mathrm{D}$ is yet to become an integral part of metacommunity theory. When we allowed species to modify habitat quality, major differences among species of different specialization (Fig. 4) 
emerged and were accompanied by strong non-linearities in other pivotal variables (Fig. 5).

Together, they warn against a simple research strategy. Nevertheless, we see a realm of general

possibilities around which a more calibrated strategy might grow (cf. Fig. 2):

1. In low dimensional systems, one dimension may suffice for prediction.

2. In high dimensional (or complex) systems:

a. Directional C-D may be detected by linear models of the 4Ds - models capable of capturing main effects and modifying effects of each dimension.

b. Reciprocal C-D will be difficult to detect because of non-linearities arising from "backand-forth" among the dimensions. Dynamic models may be needed to quickly explore generic behaviors as opposed to a strategy of testing a limited number of models against convenient natural systems.

The above suggests that remedies will require recognizing where $\mathrm{C}-\mathrm{D}$ plays a significant role and a protocol for studies aiming testing ideas about the mechanisms their consequences in such systems.

Research strategy - Recognizing $C-D$

As C-D makes things more difficult, it also makes them more interesting. Although no sound and widely accepted methodology exist to analyze complex systems such as MCs (Ladyman et al. 2013), statistical perspective advances (Desjardins-Proulx et al. 2019) promise help, even if it may demand large amounts of data to work effectively. First, high reciprocal C-D has to be identified in the system. This can be done by: 
a. Modelling: represent a system in 4D and tentatively determine whether one or more dimensions change in response to the state of one or more remaining dimensions.

b. Comparisons: examine a large sample of similar systems to determine whether some diverge from observed trends without an explanation by the first order C-D (Table 1). A lack of such an explanation might be diagnostic of another order of C-D exerting dominant influence.

c. Experiment: at micro (lab), meso, or macroscale track the metrics of 4D while manipulating or using a 'natural' experiment to determine whether reciprocal, non-linear effects occur.

\section{Research strategy - investigating high C-D systems}

Next, to refine grounds for a theoretical framework and testable hypotheses, two principles for investigating complex systems can help:

a. reducing a system complexity by abstracting fundamental dimensions or constraining them by holding some constant (experimentally) or within narrow limits (modelling) and examining outcomes. At the 4D level, it may be best to first pose hypotheses about expected trends in responses variables (species richness, stability, or other ecosystem level properties), along gradients of species interactions (strength, sign), inter-habitat differences (species independent vs species dominated), specialization (adaptable vs rigid) or dispersal (effectively low vs high). The answers here will provide coarse, high variance clouds of cases for which more specific hypothesis may be needed. Thus, one can move to

b. seeking mechanistic explanation at a different resolution - second order interactions (Table 1). Here, when all 4D interact reciprocally, testable predictions examined in a 
stepwise fashion, one variable at a time, may lead to uncover source of C-D. The result of the test can then be used in developing a prediction for the next variable, until the process converges to a solution. A less formal approach might use a combination of educated guesses, available data, and filling the missing information by simulations.

c. Still another strategy may be, in analogy to the sibling problem of treatment interference, designing experiments or data collection to estimate interference (C-D more broadly), with a corresponding interpretation approaches (Kimmel et al. 2021).

It is of interest whether we can test simple hypotheses about the effects, for instance, of spatial configuration of habitat patches on dispersal and its consequences. In such cases, if we wish to test whether patch arrangement in space (stochastic, regular, size structured, close, distant or any mix of these) affects species richness, we probably can. Yet, the result will remain suspect until shown otherwise: An acceptable test would require a demonstration that specialization gradient, habitat properties other than those explicitly tested, and species interactions have not been meaningfully modified by the configuration tested relative to a null configuration. As in most cases they will, an array of methods hinted above may be called for. When the latter is the case, a relatively simple mathematical method called the Walsh-Hadamard transform could be adapted to show how higher-order interactions among species influence a system variable of interest (Yitbarek et al. 2021).

Testing traditional MC models should best follow the strategies above because C-D renders simple tests based on data fitting at best inconclusive if not unreliable, despite sound statistical results. Although reliance on fundamental dimensions remains firmly at the core of MC, specific test of various model versions may require novel approaches. Recognition that the 4D not only interact in determining the behavior of a community, but also co-determine each other 
significantly, may unlock a sounder, even if more challenging, path to an integration of community processes with broader scale phenomena - an implicit motivation for MC framework. Depending on the level of specificity that an empirical test will require the dialog between the framework and data should follow a stepwise process from general to more specific predictions. These may be cast as a hierarchy of interactions (Table 1). The most basic predictions will draw on the $4 \mathrm{D}$ while more specific predictions will be nested within general predictions and represent higher order interactions. We suggest that these interactions constitute incipient hypotheses of increasing specificity. In the long run, a promising approach to dealing with C-D may involve converting dimensions to fields and linking these fields in ways analogous to those used in physics or sociology (e.g., Martin 2003; O'Dwyer \& Green 2010).

\section{Acknowledgments}

We thank Bryan Brown, Mathew Leibold, James Orr, Rob Pringle, and Patrick Thompson for encouragement and many helpful suggestions on the earlier versions of the manuscript and. This research was supported by NSERC Discovery Program (JK), and an NSERC undergraduate scholarship (JY).

\section{References}

Abrams, P.A. (2007). Habitat choice in predator-prey systems: Spatial instability due to interacting adaptive movements. Am Nat, 169, 581-594. 
Arnoldi, J.-F., Loreau, M. \& Haegeman, B. (2019). The inherent multidimensionality of temporal variability: how common and rare species shape stability patterns. Ecol Lett, 22, 15571567.

Atkins, J.L., Long, R.A., Pansu, J., Daskin, J.H., Potter, A.B., Stalmans, M.E. et al. (2019). Cascading impacts of large-carnivore extirpation in an African ecosystem. Science, 364, 173177.

Boulangeat, I., Gravel, D. \& Thuiller, W. (2012). Accounting for dispersal and biotic interactions to disentangle the drivers of species distributions and their abundances. Ecol Lett, 15, 584-593.

Brown, B.L., Sokol, E.R., Skelton, J. \& Tornwall, B. (2017). Making sense of metacommunities: dispelling the mythology of a metacommunity typology. Oecologia, 183, 643-652.

Cadotte, M.W. \& Tucker, C.M. (2017). Should Environmental Filtering be Abandoned? Trends Ecol Evol, 32, 429-437.

Chamberlain, S.A., Bronstein, J.L. \& Rudgers, J.A. (2014). How context dependent are species interactions? Ecol Lett, 17, 881-890.

Chase, J.M. \& Leibold, M.A. (2003). Ecological niches: Linking classical and contemporary approaches. University of Chicago Press, Chicago.

Desjardins-Proulx, P., Poisot, T. \& Gravel, D. (2019). Artificial intelligence for ecological and evolutionary synthesis. Front Ecol Evol, 7.

Deutsch, D. (2013). Constructor theory. Synthese, 190, 4331-4359.

Duffy, J.E. (2002). Biodiversity and ecosystem function: the consumer connection. Oikos, 99, 201-219. 
Filotas, E., Grant, M., Parrott, L. \& Rikvold, P.A. (2010). Positive interactions and the emergence of community structure in metacommunities. $J$ Theor Biol, 266, 419-429.

Fronhofer, E.A., Klecka, J., Melián, C.J. \& Altermatt, F. (2015). Condition-dependent movement and dispersal in experimental metacommunities. Ecol Lett, 18, 954-963.

Fulton, E.A., Blanchard, J.L., Melbourne-Thomas, J., Plagányi, É.E. \& Tulloch, V.J.D. (2019). Where the Ecological Gaps Remain, a Modelers' Perspective. Front Ecol Evol, 7.

Gonzalez, A., Germain, R.M., Srivastava, D.S., Filotas, E., Dee, L.E., Gravel, D. et al. (2020). Scaling-up biodiversity-ecosystem functioning research. Ecol Lett, 23, 757-776.

Grainger, T.N. \& Gilbert, B. (2016). Dispersal and diversity in experimental metacommunities: linking theory and practice. Oikos, 125, 1213-1223.

Gravel, D., Mouquet, N., Loreau, M. \& Guichard, F. (2010). Patch Dynamics, Persistence, and Species Coexistence in Metaecosystems. Am Nat, 176, 289-302.

Grilli, J., Rogers, T. \& Allesina, S. (2016). Modularity and stability in ecological communities. Nat Commun, 7, 12031.

Guichard, F., Zhang, Y.X. \& Lutscher, F. (2019). The emergence of phase asynchrony and frequency modulation in metacommunities. JTheor Ecol, 12, 329-343.

Guzman, L.M., Germain, R.M., Forbes, C., Straus, S., O'Connor, M.I., Gravel, D. et al. (2019). Towards a multi-trophic extension of metacommunity ecology. Ecol Lett, 22, 19-33.

Haegeman, B. \& Loreau, M. (2014). General relationships between consumer dispersal, resource dispersal and metacommunity diversity. Ecol Lett, 17, 175-184. 
Jabot, F. \& Bascompte, J. (2012). Bitrophic interactions shape biodiversity in space. Proc Natl Acad Sci USA, 109, 4521-4526.

Kimbro, D.L., Byers, J.E., Grabowski, J.H., Hughes, A.R. \& Piehler, M.F. (2014). The biogeography of trophic cascades on US oyster reefs. Ecol Lett, 17, 845-854.

Kimmel, K., Dee, L.E., Avolio, M.L. \& Ferraro, P.J. (2021). Causal assumptions and causal inference in ecological experiments. Trends Ecol.Evol., in press.

Kolasa, J. \& Li, B.-L. (2003). Removing the confounding effect of habitat specialization reveals stabilizing contribution of diversity to species variability. Biol Lett, 9, 1-4.

Ladyman, J., Lambert, J. \& Wiesner, K. (2013). What is a complex system? European J Phil Sci, 3, 33-67.

Lawton, J.H. (1999). Are there general laws in ecology? Oikos, 84, 177-192.

Leibold, M.A., Holyoak, M., Mouquet, N., Amarasekare, P., Chase, J.M., Hoopes, M. et al. (2004). The metacommunity concept: a framework for multi-scale community ecology. Ecol Lett, 7, 601-613.

Leibold, M.A., Javiera, R., Blanchet, F.G., De Mester, L., Gravel, D., Hartig, F. et al. (2020). The Internal Structure of Metacommunities. In: bioRxiv.

Liao, J.B., Bearup, D. \& Fagan, W.F. (2020). The role of omnivory in mediating metacommunity robustness to habitat destruction. Ecology, 101.

Logue, J.B., Mouquet, N., Peter, H., Hillebrand, H. \& Grp, M.W. (2011). Empirical approaches to metacommunities: a review and comparison with theory. Trends Ecol Evol, 26, 482-491. 
MacDougall, A.S., Harvey, E., McCune, J.L., Nilsson, K.A., Bennett, J., Firn, J. et al. (2018). Context-dependent interactions and the regulation of species richness in freshwater fish. Nat Commun, 9, 973.

Marleau, J.N. \& Guichard, F. (2019). Meta-ecosystem processes alter ecosystem function and can promote herbivore-mediated coexistence. Ecology, 100, 1-11.

Martin, J.L. (2003). What is field theory? American Journal of Sociology, 109, 1-49.

Massol, F., Gravel, D., Mouquet, N., Cadotte, M.W., Fukami, T. \& Leibold, M.A. (2011).

Linking community and ecosystem dynamics through spatial ecology. Ecol Lett, 14, 313-323.

Miller, T.E. \& Kneitel, J.M. (2005). Inquiline communities in pitcher plants as a prototypical metacommunity. In: Metacommunities: spatial dynamics and ecological communities (eds. Holyoak, M, Leibold, MA \& Holt, RD). University of Chicago Press Chicago.

Miller, T.E. \& terHorst, C.P. (2012). Testing successional hypotheses of stability, heterogeneity, and diversity in pitcher-plant inquiline communities. Oecologia, 170, 243-251.

Mougi, A. \& Kondoh, M. (2012). Diversity of interaction types and ecological community stability. Science, 337, 349-351.

Newman, E.A., Kennedy, M.C., Falk, D.A. \& McKenzie, D. (2019). Scaling and Complexity in Landscape Ecology. Front Ecol Evol, 7, doi /10.3389/fevo.2019.00293

O'Dwyer, J.P. \& Green, J.L. (2010). Field theory for biogeography: a spatially explicit model for predicting patterns of biodiversity. Ecol Lett, 13, 87-95. 
Orr, J.A., Vinebrooke, R.D., Jackson, M.C., Kroeker, K.J., Kordas, R.L., Mantyka-Pringle, C. et al. (2020). Towards a unified study of multiple stressors: divisions and common goals across research disciplines. Proc Roy Soc B: Biol Sci, 287, 2020.0421.

Paine, R.T. (1984). Ecological determinism in the competition for space. Ecology, 65, 13391348.

Pansu, J., Guyton, J.A., Potter, A.B., Atkins, J.L., Daskin, J.H., Wursten, B. et al. (2019).

Trophic ecology of large herbivores in a reassembling African ecosystem. J Ecology, 107, 13551376.

Ryberg, W.A., Smith, K.G. \& Chase, J.M. (2012). Predators alter the scaling of diversity in prey metacommunities. Oikos, 121, 1995-2000.

Song, C., Von Ahn, S., Rohr, R.P. \& Saavedra, S. (2020). Towards a probabilistic understanding about the context-dependency of species interactions. Trends Ecol \& Evol 35, 384-396.

Stachowicz, J.J. (2001). Mutualism, Facilitation, and the Structure of Ecological Communities: Positive interactions play a critical, but underappreciated, role in ecological communities by reducing physical or biotic stresses in existing habitats and by creating new habitats on which many species depend. BioScience, 51, 235-246.

Thompson, P.L., Guzman, L.M., De Meester, L., Horvath, Z., Ptacnik, R., Vanschoenwinkel, B. et al. (2020). A process-based metacommunity framework linking local and regional scale community ecology. Ecol Lett, 23, 1314-1329. 
Thompson, P.L., Rayfield, B. \& Gonzalez, A. (2017). Loss of habitat and connectivity erodes species diversity, ecosystem functioning, and stability in metacommunity networks. Ecography, 40, 98-108.

Vanschoenwinkel, B., Buschke, F. \& Brendonck, L. (2013). Disturbance regime alters the impact of dispersal on alpha and beta diversity in a natural metacommunity. Ecology, 94, 2547-2557.

Wang, R., Aylwin, R., Barwell, L., Chen, X.-Y., Chen, Y., Chou, L.-S. et al. (2015). The fig wasp followers and colonists of a widely introduced fig tree, Ficus microcarpa. Insect Conserv Diver, 8, 322-336.

Williams, P. (2005). Does specialization explain rarity and decline among British bumblebees? A response to Goulson et al. Biol Conserv, 122, 33-43.

Yeakel, J.D., Pires, M.M., de Aguiar, M.A.M., O’Donnell, J.L., Guimarães, P.R., Gravel, D. et al. (2020). Diverse interactions and ecosystem engineering can stabilize community assembly. Nat Commun, 11, 3307.

Yitbarek, S., Guittar, J., Knutie, S.A. \& Ogbunugafor, C.B. (2021). Deconstructing taxa $x$ environment interactions in the microbiota: A theoretical examination. bioRxiv, 647156.

Yu, D.W., Wilson, H.B., Frederickson, M.E., Palomino, W., De la Colina, R., Edwards, D.P. et al. (2004). Experimental demonstration of species coexistence enabled by dispersal limitation. $J$ Anim Ecol, 73, 1102-1114.

Zélé, F., Magalhães, S., Kéfi, S. \& Duncan, A. (2018). Ecology and evolution of facilitation among symbionts. Nat Commun, 9. 
bioRxiv preprint doi: https://doi.org/10.1101/2021.09.26.461405; this version posted September 26, 2021. The copyright holder for this preprint (which was not certified by peer review) is the author/funder, who has granted bioRxiv a license to display the preprint in perpetuity. It is made available under aCC-BY-NC-ND 4.0 International license.

\section{Figures}

Fig. 1.

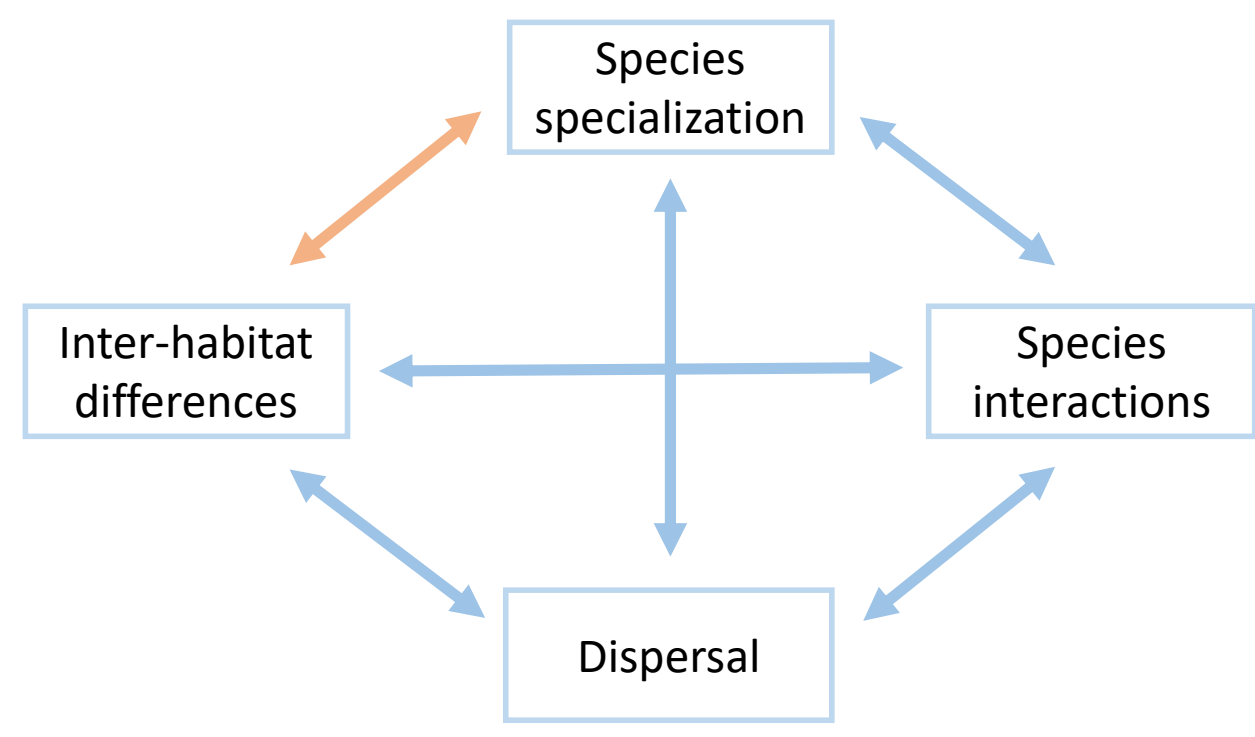

Reciprocal influence;

Reciprocal definition and influence 
Fig. 2.

(a) Directional context-dependency

\section{Outcome}

species richness

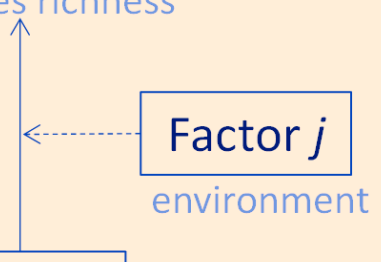

Factor $i$

dispersal

(c) Directional MCD

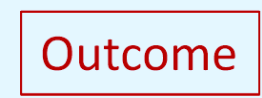

species richness

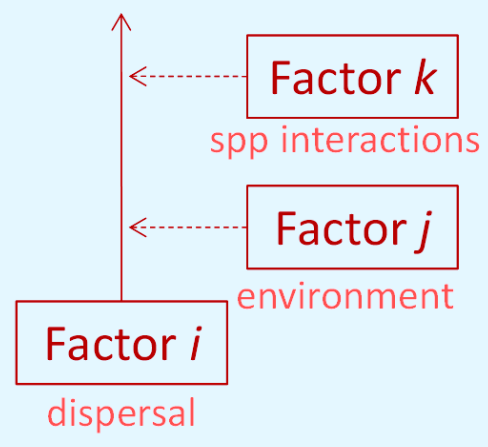

(b) Reciprocal context-dependency

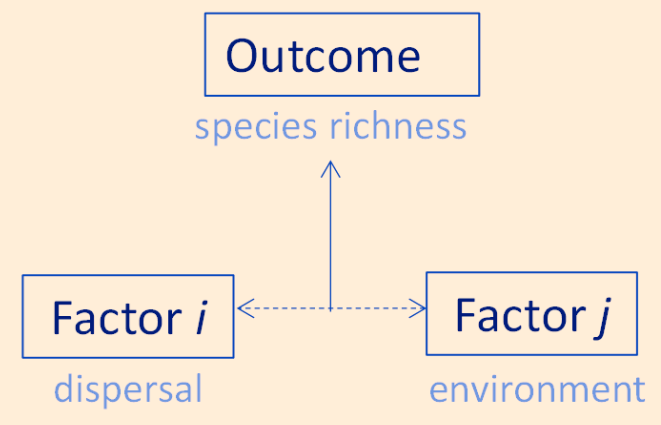

(d) Reciprocal MCD

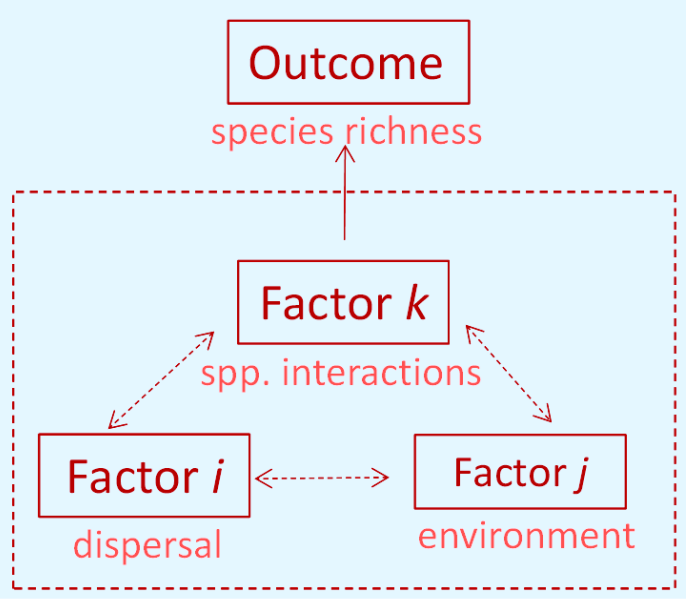


bioRxiv preprint doi: https://doi.org/10.1101/2021.09.26.461405; this version posted September 26, 2021. The copyright holder for this preprint (which was not certified by peer review) is the author/funder, who has granted bioRxiv a license to display the preprint in perpetuity. It is made available under aCC-BY-NC-ND 4.0 International license.

Fig. 3.

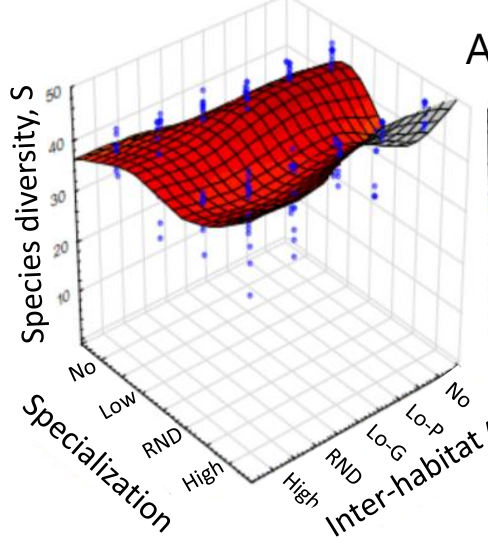

SI Pos SS, SG

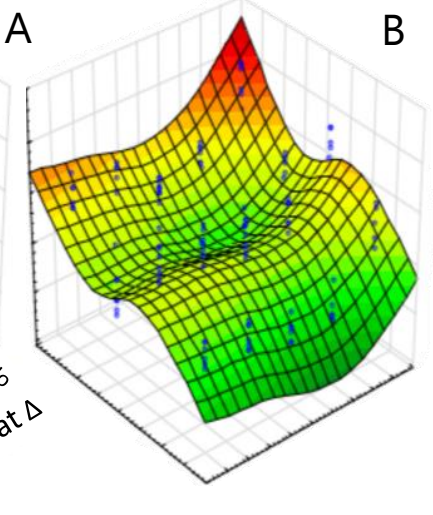

SI Pos SG, GG

$B$

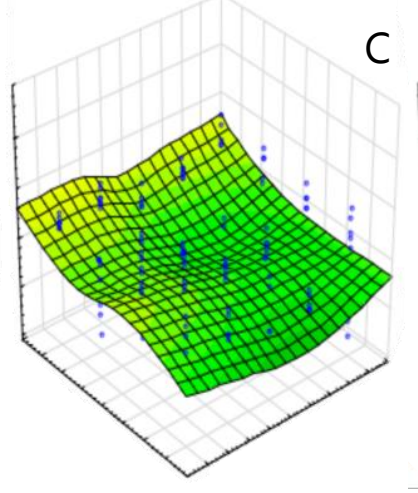

SI High

C

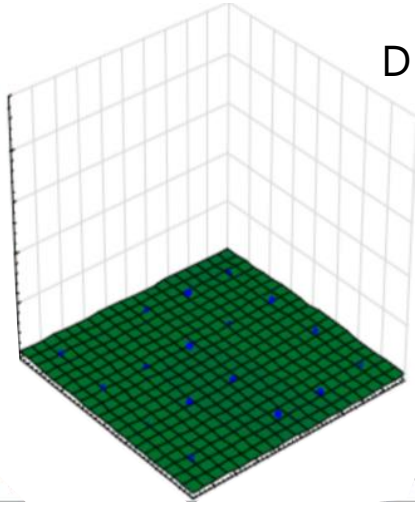

SI Neg SS, GG
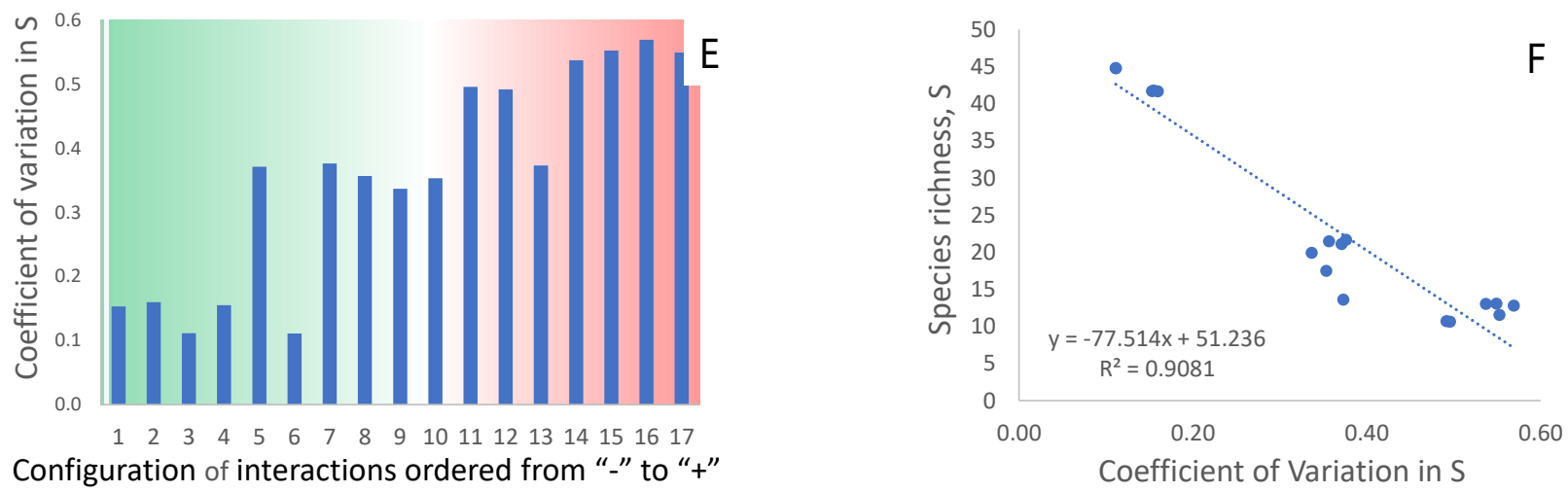
bioRxiv preprint doi: https://doi.org/10.1101/2021.09.26.461405; this version posted September 26, 2021. The copyright holder for this preprint (which was not certified by peer review) is the author/funder, who has granted bioRxiv a license to display the preprint in perpetuity. It is made available under aCC-BY-NC-ND 4.0 International license.

Fig. 4.
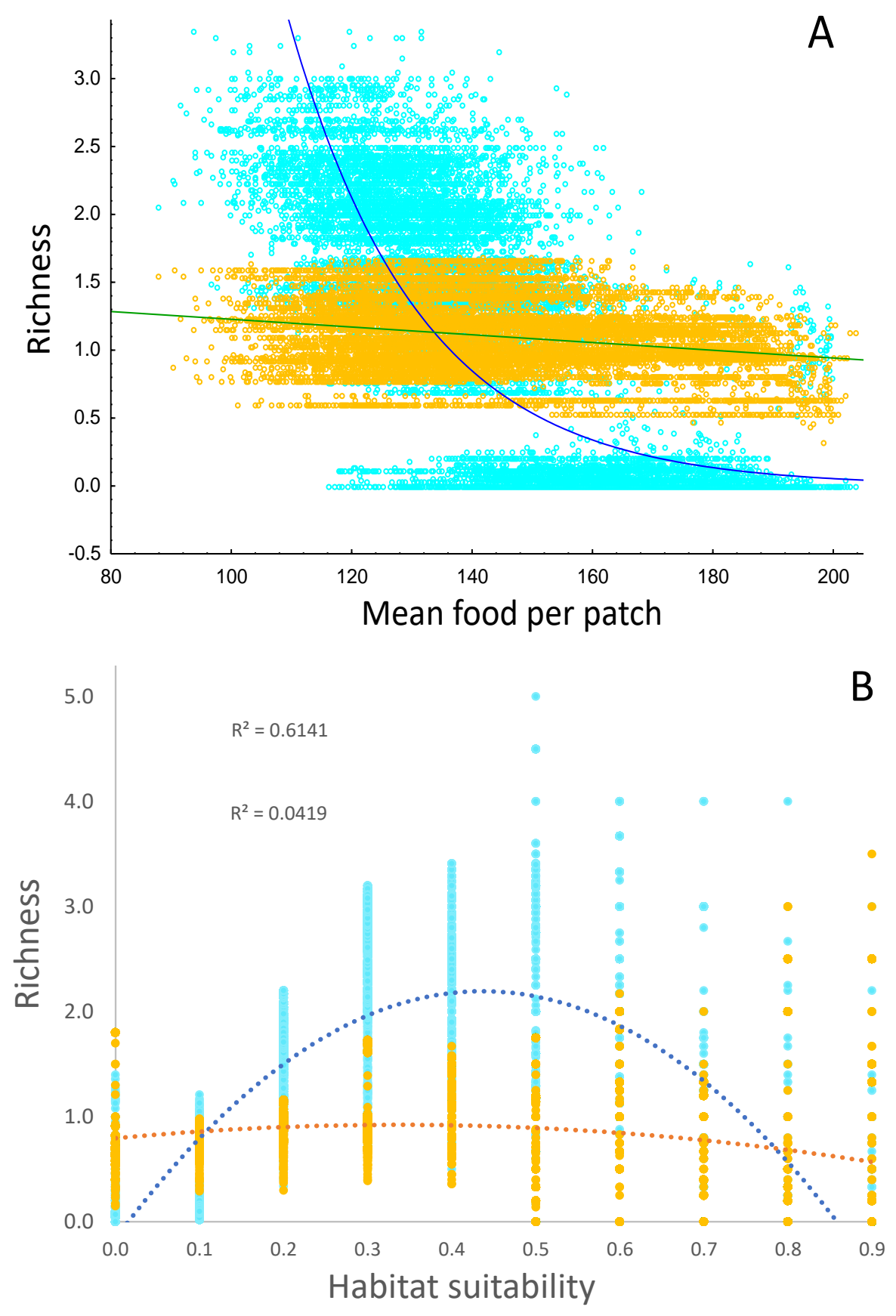
bioRxiv preprint doi: https://doi.org/10.1101/2021.09.26.461405; this version posted September 26, 2021. The copyright holder for this preprint (which was not certified by peer review) is the author/funder, who has granted bioRxiv a license to display the preprint in perpetuity. It is made available under aCC-BY-NC-ND 4.0 International license.

Fig. 5
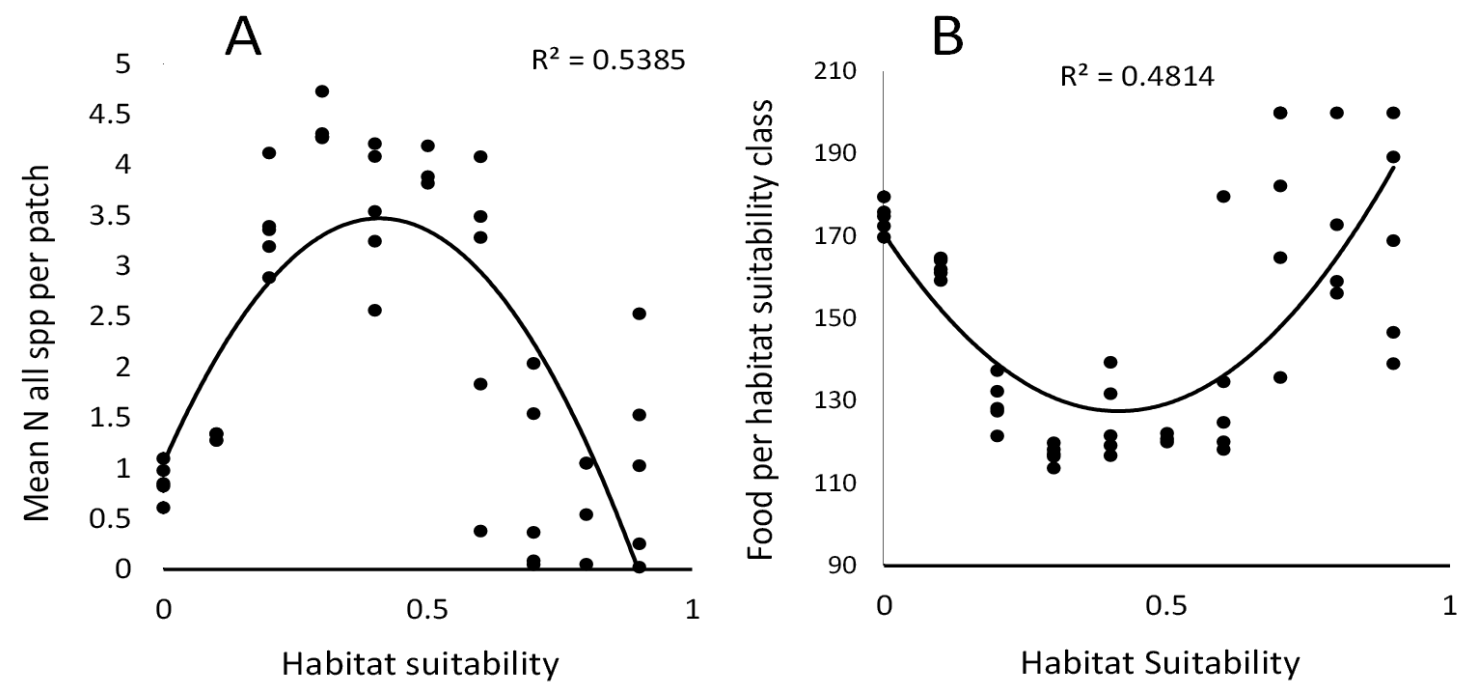


\section{Figure legends}

Fig. 1. Model structure: 4 dimensions and types of relationships among them. All four dimensions are either known or have the potential to reciprocally affect others, directly and indirectly. We also propose that species specialization and inter-habitat differences co-define each other (i.e., one cannot be meaningfully defined without the other) in addition to trading impacts.

Fig. 2. Basic ways in which multiple factors can combine into several types of contextdependency, C-D, depending on how they interact. a-d differ in the number of factors and reciprocity of interactions ( $\mathrm{a}$ and $\mathrm{d}$ - no reciprocity), $\mathrm{b}$ and $\mathrm{c}$ - reciprocity among two or more factors affect the outcome.

Fig. 3. Different combination of interactions - on the gradient from negative to positive (a sample of all 18 available treatment combinations) - impact expected species richness, $\mathrm{S}$ (landscape mean). A-D - extreme positive (A) to negative (D) interaction configurations; B - the last positive, $\mathrm{C}$ - a random mix of positive and negative interactions; $\mathrm{E}$ - normalized variation increases with the shift towards negative interactions on a gradient of model treatments (red background); $\mathrm{F}$ - the increase in variation is correlated with the loss of species richness. X-axes show Specialization 'treatments'; y - axes show Inter-Habitat differences. Note differences in S and a loss of specialists near the middle range of species interactions. Pos - positive, Neg - 
negative, $\mathrm{S}$ - specialist, G-generalist, first letter - S or G affect the species $\mathrm{S}$ or $\mathrm{G}$ (second letter). Lo-G - low inter-habitat differences, good habitat; Lo-P - low inter-habitat differences, poor habitat. Complete set of results in Supplementary materials, Appendix 2, Fig. 2.1.

Fig. 4. A - Species specialists (light blue) and generalist (goldenrod) richness, S, on the gradient of habitat suitability. B- Relationship between consumable resources and species richness of specialists and generalists. Diversity of specialists is associated with the amount of food resource (energy units in UMM), with a non-linear impact that is prominent in the middle of the habitat suitability range.

Fig. 5. Mean food per patch suitability class (A) and aggregate abundance, $\mathrm{N}_{\text {all }}$, of species present (B) are related to habitat suitability class. Habitat suitability here represents initial 'abiotic' conditions that a species must satisfy. Total species abundance, N, correlates in a nonlinear fashion with habitat suitability and provides functional explanation for specialist richness trend in Figure 4, but not for generalists. 
Table 1. Interactions among dimensions - the raw material for hypotheses.

4D permutations underlying the context-dependency of metacommunity outcomes can serve as working hypotheses. $\mathrm{D}=$ dispersal; $\mathrm{H}$ = habitat heterogeneity; $\mathrm{I}=$ species interactions; $\mathrm{S}=$ specialization. + and - denote positive and negative effects of an individual factor on local species richness. The sign of factor interaction is given as the product of $+\mathrm{s}$ and $-\mathrm{s}$. Only combinations including dispersal are presented to emphasize metacommunity processes.

\begin{tabular}{|c|c|c|c|c|c|c|}
\hline $\begin{array}{l}\text { Order of } \\
\text { context- } \\
\text { dependency }\end{array}$ & D & $\mathbf{H}$ & $\mathbf{I}$ & $\mathbf{S}$ & $\begin{array}{c}\text { Possible } \\
\text { mechanism }\end{array}$ & Description \\
\hline \multirow[t]{4}{*}{ First } & + & & & & Rescue effects & $\begin{array}{l}\text { Dispersal alone promotes species } \\
\text { richness }\end{array}$ \\
\hline & & + & & & Habitat diversity & $\begin{array}{l}\text { Heterogeneous habitats host more } \\
\text { species }\end{array}$ \\
\hline & & & + & & Mutualisms & $\begin{array}{l}\text { Positive interactions among species } \\
\text { promote richness; negative interactions } \\
\text { reduce it }\end{array}$ \\
\hline & & & & + & Niche partitioning & $\begin{array}{l}\text { Species specialize on a subset of } \\
\text { habitats or resources }\end{array}$ \\
\hline
\end{tabular}




\begin{tabular}{|c|c|c|c|c|c|c|}
\hline \multirow[t]{6}{*}{ Second } & + & - & & & Species sorting & $\begin{array}{l}\text { Dispersal in combination with habitat } \\
\text { heterogeneity reduces richness }\end{array}$ \\
\hline & + & + & & & Mass effects & $\begin{array}{l}\text { Dispersal adds species to low quality } \\
\text { habitats }\end{array}$ \\
\hline & + & & - & & Patch dynamics & $\begin{array}{l}\text { Dispersal enables escape from negative } \\
\text { interactions }\end{array}$ \\
\hline & + & & + & & $\begin{array}{l}\text { Mutualistic patch } \\
\text { dynamics }\end{array}$ & $\begin{array}{l}\text { Dispersal connects mutualists in } \\
\text { different patches to increase local } \\
\text { richness }\end{array}$ \\
\hline & + & & & - & $\begin{array}{l}\text { Competition or } \\
\text { predation of } \\
\text { specialists }\end{array}$ & $\begin{array}{l}\text { Dispersing generalists outcompete or } \\
\text { prey upon specialists }\end{array}$ \\
\hline & + & & & + & $\begin{array}{l}\text { Rescue effects of } \\
\text { specialists }\end{array}$ & $\begin{array}{l}\text { Dispersal connects and enables survival } \\
\text { of specialist species }\end{array}$ \\
\hline \multirow[t]{2}{*}{ Third } & + & + & + & & $\begin{array}{l}\text { Mutualistic mass } \\
\text { effects }\end{array}$ & $\begin{array}{l}\text { Positive interactions among dispersing } \\
\text { species enhance richness in } \\
\text { heterogenous habitats }\end{array}$ \\
\hline & + & + & - & & $\begin{array}{l}\text { Antagonistic mass } \\
\text { effects }\end{array}$ & $\begin{array}{l}\text { Dispersing competitors lead to niche } \\
\text { partitioning in heterogenous habitats }\end{array}$ \\
\hline
\end{tabular}




\begin{tabular}{|c|c|c|c|c|c|}
\hline+ & - & + & & $\begin{array}{l}\text { Mutualistic } \\
\text { species sorting }\end{array}$ & $\begin{array}{l}\text { Positive interactions among species } \\
\text { enhance survival in sink habitats }\end{array}$ \\
\hline+ & - & - & & $\begin{array}{l}\text { Community- } \\
\text { enhanced species } \\
\text { sorting }\end{array}$ & $\begin{array}{l}\text { Species sorting exacerbated by negative } \\
\text { species interactions }\end{array}$ \\
\hline+ & + & & + & $\begin{array}{l}\text { Heterogeneous } \\
\text { rescue effects of } \\
\text { specialists }\end{array}$ & $\begin{array}{l}\text { Dispersal among diverse habitats } \\
\text { enables survival of specialists }\end{array}$ \\
\hline+ & - & & + & $\begin{array}{l}\text { Specialist species } \\
\text { sorting }\end{array}$ & $\begin{array}{l}\text { Specialists are filtered by local } \\
\text { environment more than generalists }\end{array}$ \\
\hline+ & - & & - & $\begin{array}{l}\text { Generalist species } \\
\text { sorting }\end{array}$ & $\begin{array}{l}\text { Generalists are filtered by local } \\
\text { environment more than specialists }\end{array}$ \\
\hline+ & & + & + & $\begin{array}{l}\text { Mutualistic patch } \\
\text { dynamics of } \\
\text { specialists }\end{array}$ & $\begin{array}{l}\text { Dispersal of mutual specialists into } \\
\text { matrix enhances local survival and } \\
\text { richness }\end{array}$ \\
\hline+ & & - & + & $\begin{array}{l}\text { Specialist patch } \\
\text { dynamics }\end{array}$ & $\begin{array}{l}\text { Dispersal of specialists enables escape } \\
\text { from negative interactions }\end{array}$ \\
\hline+ & & - & - & $\begin{array}{l}\text { Generalist patch } \\
\text { dynamics }\end{array}$ & $\begin{array}{l}\text { Dispersal enables competition release in } \\
\text { generalists }\end{array}$ \\
\hline
\end{tabular}




\begin{tabular}{|c|c|c|c|c|c|c|}
\hline \multirow[t]{6}{*}{ Fourth } & + & + & + & + & $\begin{array}{l}\text { Mutualistic mass } \\
\text { effects of } \\
\text { specialists }\end{array}$ & $\begin{array}{l}\text { Dispersal boosts persistence of } \\
\text { mutualistic interactions in patches, }\end{array}$ \\
\hline & + & - & + & + & $\begin{array}{l}\text { Mutualistic } \\
\text { species sorting of } \\
\text { specialists }\end{array}$ & $\begin{array}{l}\text { Inter-habitat differences deny ED to } \\
\text { specialists and disrupt support for } \\
\text { mutualism }\end{array}$ \\
\hline & + & - & - & + & $\begin{array}{l}\text { Community- } \\
\text { enhanced species } \\
\text { sorting of } \\
\text { specialists }\end{array}$ & $\begin{array}{l}\text { Both inter-habitat differences and } \\
\text { negative interactions inhibit specialist } \\
\text { performance to the point of exclusion } \\
\text { in some patches }\end{array}$ \\
\hline & + & - & - & - & $\begin{array}{l}\text { Community- } \\
\text { enhanced species } \\
\text { sorting of } \\
\text { generalists }\end{array}$ & $\begin{array}{l}\text { Only the best dispersers with high } \\
\text { tolerance of the totality of habitat } \\
\text { conditions will persist in MC landscape }\end{array}$ \\
\hline & + & + & - & + & $\begin{array}{l}\text { Antagonistic mass } \\
\text { effects of } \\
\text { specialists }\end{array}$ & $\begin{array}{l}\text { Generalists add to specialists' } \\
\text { population variability }\end{array}$ \\
\hline & + & + & - & - & $\begin{array}{l}\text { Antagonistic mass } \\
\text { effects of } \\
\text { generalists }\end{array}$ & $\begin{array}{l}\text { Generalist presence reduces } \\
\text { establishment of arriving specialists }\end{array}$ \\
\hline
\end{tabular}


bioRxiv preprint doi: https://doi.org/10.1101/2021.09.26.461405; this version posted September 26, 2021. The copyright holder for this preprint (which was not certified by peer review) is the author/funder, who has granted bioRxiv a license to display the preprint in perpetuity. It is made available under aCC-BY-NC-ND 4.0 International license.

\begin{tabular}{|l|l|l|l|l|l|l|}
\hline & + & + & + & - & Mutualistic mass \\
effects of & Enhances the effect of establishment \\
generalists & denial to specialists \\
\hline
\end{tabular}

